\title{
Surgical insights into Parkinson's disease
}

\author{
Erlick A C Pereira Tipu Z Aziz
}

J R Soc Med 2006;99:238-244

\section{SUMMARY}

Surgery for Parkinson's disease was popularized in the midtwentieth century before the advent of effective medical therapies. Early lesioning treatments contributed to our understanding of the functional anatomy of Parkinson's disease. Observations of the limitations and long-term complications of established pharmacological therapies for Parkinson's disease, together with major contributions from animal research to elucidate the roles of the basal ganglia in movement disorders, inspired a recent renaissance in neurosurgical interventions for Parkinson's disease including deep brain stimulation; this continues to yield much neurophysiological information. The development of potentially restorative treatment modalities, such as gene therapy, neural transplantation and nanotechnology, hold much promise for surgery, both therapeutically and in revealing further insights into Parkinson's disease pathophysiology.

\section{INTRODUCTION}

Parkinson's disease is a slowly progressive, neurodegenerative disease characterized by tremor, rigidity, bradykinesia and postural instability. It is the most common movement disorder in middle or late life with a prevalence of about $0.3 \%$ of the general population, rising to $1 \%$ in people over 60 years of age. ${ }^{1}$ Approximately 130000 people suffer from it in the UK and it presents an increasing burden in our ageing population. Pathological findings in Parkinson's disease demonstrate greatly diminished neuromelanin pigmented neurons in the substantia nigra of the basal ganglia with associated gliosis, and Lewy bodies present in many remaining neurons. Its cardinal biochemical feature is dopamine deficiency in the striatum, another basal ganglia structure. The brain structures currently targeted in surgery for Parkinson's disease are predominantly in the basal ganglia and include the globus pallidus interna, ventralis intermedius nucleus of the thalamus, and subthalamic nucleus (Figure 1).

James Parkinson, in his original 1817 Essay on The Shaking Palsy, gave an account of six patients in which he noted signs of tremor, festinating gait and flexed posture. ${ }^{2}$

Oxford Functional Neurosurgery, Department of Neurological Surgery, The Radcliffe Infirmary, Oxford OX2 6HE, UK

Correspondence to: Professor T Z Aziz
He commented in the monograph that '. . . until we are better informed respecting the nature of this disease the employment of internal medicines is scarcely warrantable'. Nearly two centuries on from Parkinson's observations, and almost four decades after Cotzias' dramatic demonstration of levodopa's efficacy, ${ }^{3}$ the limitations and complications of levodopa treatment for Parkinson's disease have become well documented (Table 1). ${ }^{4}$ The now established resurgence of neurosurgery for Parkinson's disease, in particular of deep brain stimulation (DBS) for the treatment

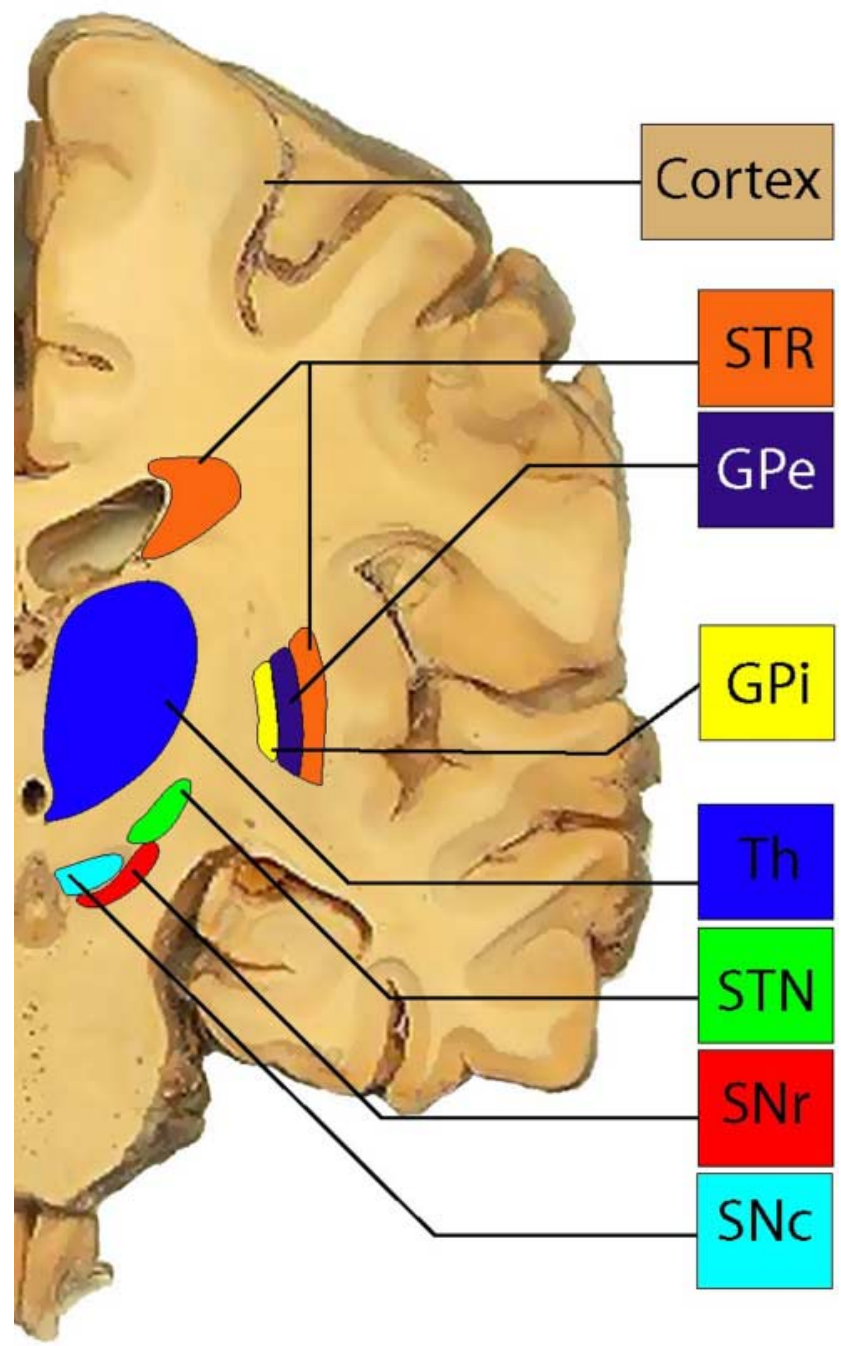

Figure 1 A coronal section through a cerebral hemisphere illustrating the basal ganglia. STR, striatum; GPe, globus pallidus pars externa; GPi, globus pallidus pars interna; Th, thalamus; subthalamic nucleus; STN, subthalamic nucleus; SNr, substantia nigra pars reticulata; SNc, substantia nigra pars compacta [in colour online] 


\begin{tabular}{ll}
\hline Hypokinetic phenomena & Hyperkinetic phenomena \\
\hline End of dose 'wearing off' bradykinesia & Peak dose dyskinesia \\
Unpredictable 'on/off' bradykinesia & Diphasic dyskinesia \\
Brief 'off' period freezing & 'Off' period dyskinesia \\
Brief 'on' period freezing & Early morning dystonia \\
Early morning akinesia or bradykinesia & Biphasic dystonia \\
\hline
\end{tabular}

of tremor and dyskinesias refractory to medication, encourages reflection upon the insights gained from surgery into the pathophysiology of the disease. Here, we consider whether surgery has informed us sufficiently to warrant 'the employment of internal medicines' and evaluate the future prospects for surgical intervention in Parkinson's.

\section{METHODS}

References were identified from the authors' reading of books and journals in neuroscience, neurology and neurosurgery; from electronic literature (Medline) searches; and through discussions with colleagues. Because of the broad nature of topics covered, accessible reviews have sometimes been cited rather than primary data papers.

\section{ABLATION AS THERAPY}

The counter-intuitive, albeit now vindicated, strategy of employing surgical ablation to improve an already impaired nervous system has its origins with Parkinson himself. He noted that the resting tremor of one of his patients disappeared with a stroke that rendered them hemiplegic. ${ }^{2}$ However, he speculated that the disease arose from medullary swelling impeding the passage of nervous influence from brain to muscle; the basal ganglia were not implicated in movement disorders until Hughlings Jackson's observations half a century after Parkinson's original description. ${ }^{5}$ Their role was not popularized until another half a century later again when Ramsey Hunt proposed that lesions to different components of the basal ganglia could cause parkinsonism, chorea and athetosis. ${ }^{6}$ His theory built upon foundations laid by Wilson in primate brain lesioning experiments using Horsley and Clarke's recently invented stereotactic apparatus. ${ }^{7,8}$ The 'inhibition release' hypotheses of Hughlings Jackson, Ramsey Hunt, Wilson and others prevailed until the 1980s; despite their inability to account for many clinical sequelae of movement disorders, for example the great variety of motor manifestations of Huntington's disease. Wilson coined the basal ganglia 'dark basements of the mind' and they remained a mystery. ${ }^{9}$ Nevertheless, the hypotheses and experimental evidence available were sufficient to encourage a host of attempts at surgical lesioning for the treatment of Parkinson's throughout the first half of the twentieth century.

Many surgeons targeted the basal ganglia, yet targets varied dramatically in brain and spine, notably including Bucy's pioneering motor cortex extirpations. ${ }^{10}$ Most operations conferred little clinical benefit, and even included thyroidectomy. ${ }^{11,12}$ As Laitinen remarked,

'When one sets out to make a historical survey of surgical attempts to relieve the tremor and rigor in Parkinson's disease, one cannot help feeling that it would have been a far easier task to list those nervous structures which have not been attacked'. ${ }^{13}$

Nevertheless, the poor results obtained by the disparate multitude of freehand surgical approaches helped, at the very least, to clarify many anatomical structures neither necessary to nor sufficient for Parkinson's.

In 1952, the American neurosurgeon Cooper operated upon a patient with the disease and inadvertently ligated their anterior choroidal artery causing infarction of the globus pallidus. His patient awoke with their tremor resolved and no deficits despite the damage done. ${ }^{14}$ Cooper's finding led to the relatively effective practice of injecting alcohol into the globus pallidus to relieve Parkinsonian tremor. The creation in 1947 of a stereotactic frame for localizing surgical targets using human brain rather than skull landmarks gave new opportunities for accurate ablation of brain structures. ${ }^{15}$ In the same decade as Cooper's discovery, Leksell utilized his own recently invented stereotactic apparatus to accurately lesion the posteroventrolateral portion of the globus pallidus interna by thermocoagulation to ameliorate parkinsonian bradykinesia and rigidity in over 200 patients. ${ }^{16-18}$ Thalamic ablation was also introduced in the early 1950s; it was found to relieve tremor and rigidity with little improvement in hypokinesia but more consistent benefits than medial, if not posteroventrolateral, pallidotomy. ${ }^{19}$ Thus, thalamotomy became the most common surgical intervention for Parkinson's disease with over 70000 patients having been operated upon by the mid 1970s, waning only as levodopa established itself as the mainstay of the 
treatment. However, the risks of ablative surgery can be significant, ${ }^{20,21 — \text { they include: }}$

- haemorrhage

- infarction

- facial palsies

- dysphagia

- visual field, speech and cognitive deficits

- affective disorders

- mortality

Furthermore, despite the empirical clinical benefit shown by such operations, they revealed little mechanistically regarding the dysfunctional circuitry underlying Parkinson's disease.

\section{ANIMAL RESEARCH}

The absence of a plausible theoretical model, juxtaposed against the clinical improvements shown during two decades of surgery and the dramatic benefits conferred by the recently discovered drug levodopa, prompted Marsden, a renowned authority on movement disorders, in 1975 to assert that

'much of the research into experimental parkinsonism and dyskinesias must be undertaken in primates, for only those animals develop the typical clinical phenomena seen in man'. ${ }^{22}$

Animal research up until then had contributed considerably towards understanding the pathophysiology and treatment of Parkinson's disease. There were notable works which included: Hughlings Jackson's primate research leading to his conclusion that unstable basal ganglia activity led to chorea; ${ }^{5}$ Sherrington's development of the decerebrate animal as a model of parkinsonian rigidity; ${ }^{23}$ Fulton's demonstrations that cerebellar tremor could be relieved by motor cortex lesions; ${ }^{24}$ Denny-Brown's many primate lesioning experiments leading to his postulate that movement disorders arise from conflicts between postural reflexes due to basal ganglia dysfunction; ${ }^{25}$ and Carlsson's demonstration that levodopa reversed akinesia in reserpinized animals. ${ }^{26}$ However, as Marsden predicted, it was the development of increasingly accurate primate models of the disease that enabled great advances in the theoretical understanding to be made.

In 1983 several cases of parkinsonism in heroin users led to the discovery that the compound 1-methyl-4-phenyl1,2,3,6-tetrahydropyridine (MPTP) induces parkinsonism in humans. ${ }^{27}$ Thus, a primate model of parkinsonism was created which remains the only mammalian model to exhibit the resting tremors and drug-induced dyskinesias seen in humans. ${ }^{28}$ Evidence gathered from several years' worth of metabolic marker studies, ${ }^{29}$ and recordings of single neuron activities in awake, moving primates enabled the conception of a theory for basal ganglia function that could finally explain the symptoms and signs of Parkinson's disease. ${ }^{30,31}$ The experiments of DeLong, Crossman and others led to a proposal that neural circuitry comprising 'direct' and 'indirect' pathways is dysfunctional in the disease (Figure 2), and also that parallel circuits linking neocortical brain structures with the basal ganglia are involved in cognitive and emotional processing. Dysfunction within such a parallel 'cortico-striato-pallido-thalamic' neuronal network explained not only motor phenomena, but provided a plausible paradigm to explain many of the cognitive, affective and behavioural changes seen in Parkinson's disease and other movement disorders and, conversely, the motor changes seen in psychiatric disorders. ${ }^{32-34}$ In the early 1990s, it was demonstrated that lesions made to the subthalamic nucleus in primates reversed the motor symptoms of MPTP-induced parkinsonism. ${ }^{35,36}$ Together with the resurgence of globus pallidus interna ablation pioneered in Sweden in the late 1980s for Parkinson's disease refractory to levodopa treatment, ${ }^{37}$ this finding and the development of DBS led to a veritable renaissance in surgical treatment for the disease.

The MPTP primate model is the most useful animal model of Parkinson's disease available presently. Primates are bipedal species whose nervous systems emulate the size and complexity of the human nervous system; and they are dexterous enough to perform the delicate motor tasks required to evaluate their motor function experimentally. The MPTP primate is not a perfect model and its utility and limitations have been comprehensively reviewed. ${ }^{38-41}$ Despite its successful mimicry of parkinsonian symptoms, one particular shortcoming is its inability to replicate the insidious onset and progressive degeneration of Parkinson's disease. Nevertheless, it is accurate enough to have proven invaluable to the preclinical investigation of both surgical and pharmacological treatments. ${ }^{42,43}$

\section{DEEP BRAIN STIMULATION}

Reversible lesioning by DBS was pioneered by Cooper for treating spasticity and epilepsy in the early 1970s, ${ }^{44}$ but was not applied to Parkinson's disease until 1987 when DBS, using indwelling electrodes inserted into the thalamus, was shown to suppress tremor. ${ }^{45}$ Bilateral DBS of either the globus pallidus interna or the subthalamic nucleus dramatically improves parkinsonian tremor, bradykinesia and rigidity (Figure 3).46,47 Approximately 30000 patients worldwide have benefited from DBS to date. However, the procedure remains limited to specialist centres, and appropriate patient selection is crucial to its successful use (Box 1). ${ }^{48}$ Few randomized clinical trials comparing DBS to pharmacological treatments have been done, ${ }^{49}$ although a 


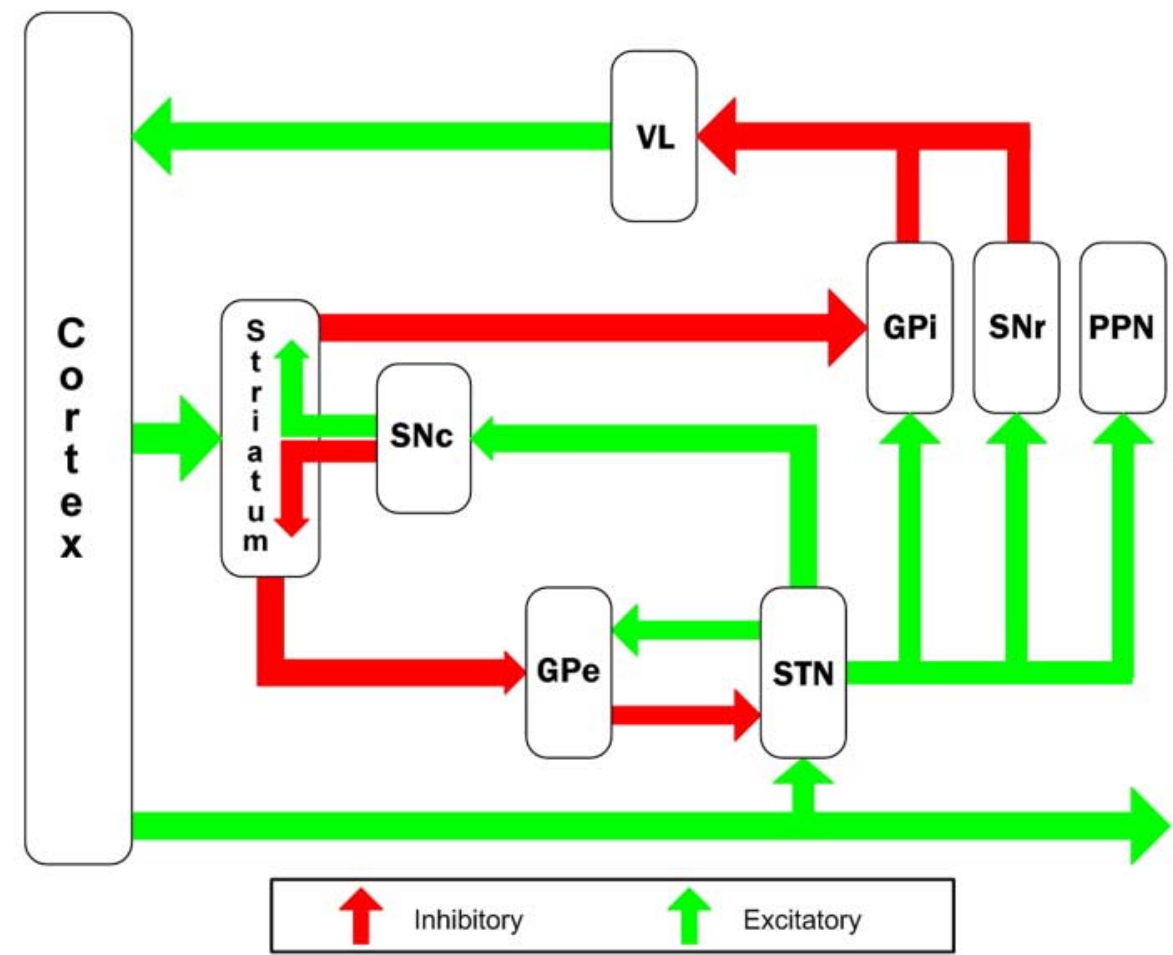

Figure 2 Basal ganglia circuitry involved in movement. GPe, globus pallidus pars externa; GPi, globus pallidus pars interna; STN, subthalamic nucleus; SNc, substantia nigra pars compacta; SNr, substantia nigra pars reticulata; VL, ventrolateral thalamus; PPN, pedunculopontine nucleus [in colour online]

large multi-centre prospective clinical trial is currently underway in the UK. ${ }^{50}$

Globus pallidus interna DBS may directly reduce medication induced dyskinesias but subthalamic nucleus DBS may achieve the same goal by enabling patients to reduce their levodopa dosage radically. While the subthalamic nucleus has recently gained wider acceptance as a surgical target, further large, prospective clinical trials are required to confirm its long-term superiority. ${ }^{51}$ The present impression is that globus pallidus interna DBS may be a superior treatment for patients with a low dyskinesia threshold and low levodopa dosage but that subthalamic nucleus DBS may be better for those using large amounts of levodopa. Also under investigation are the effects of DBS upon non-motor sequelae of Parkinson's disease: cognitive; affective and behavioural $; 5^{52}$ upon quality of life $;^{53}$ and upon the natural history of the disease. It has been speculated that subthalamic nucleus DBS is neuroprotective, inhibiting glutamatergic afferent-mediated excitotoxic damage to dopaminergic nigrostriatal neurons and thus slowing disease progression. ${ }^{54}$ However, evidence is equivocal and further research is needed. ${ }^{55}$

Current anatomical models of basal ganglia function (Figure 2) fail to explain wholly the efficacy of DBS in Parkinson's disease: in particular the finding that globus pallidus interna DBS paradoxically improves dyskinesias without deleterious effects upon motor function. ${ }^{56,57}$ One hypothesis implicates aberrantly modulated rhythmic activity in different basal ganglia neurons oscillating in synchrony at different frequency bands to account for both the pathological movements of Parkinson's disease and the efficacy of surgical lesions and DBS. ${ }^{58}$ Further research is needed, both experimentally and from electrode recordings in patients, to gain a fuller understanding of such mechanisms. Animal research also continues to reveal

\section{Box 1 Selection criteria for surgery in Parkinson's disease}

Idiopathic Parkinson's disease

Dopamine responsive symptoms

Patient desire for consistent reduction of increased duration in motor symptoms

Minimal cognitive impairment (MMSE > 24/30)

Depression or mood disorders minimal or well controlled by medication

No psychotic symptoms or hallucinations induced by medications

Good bulbar neurological function

MMSE, mini-mental state examination 


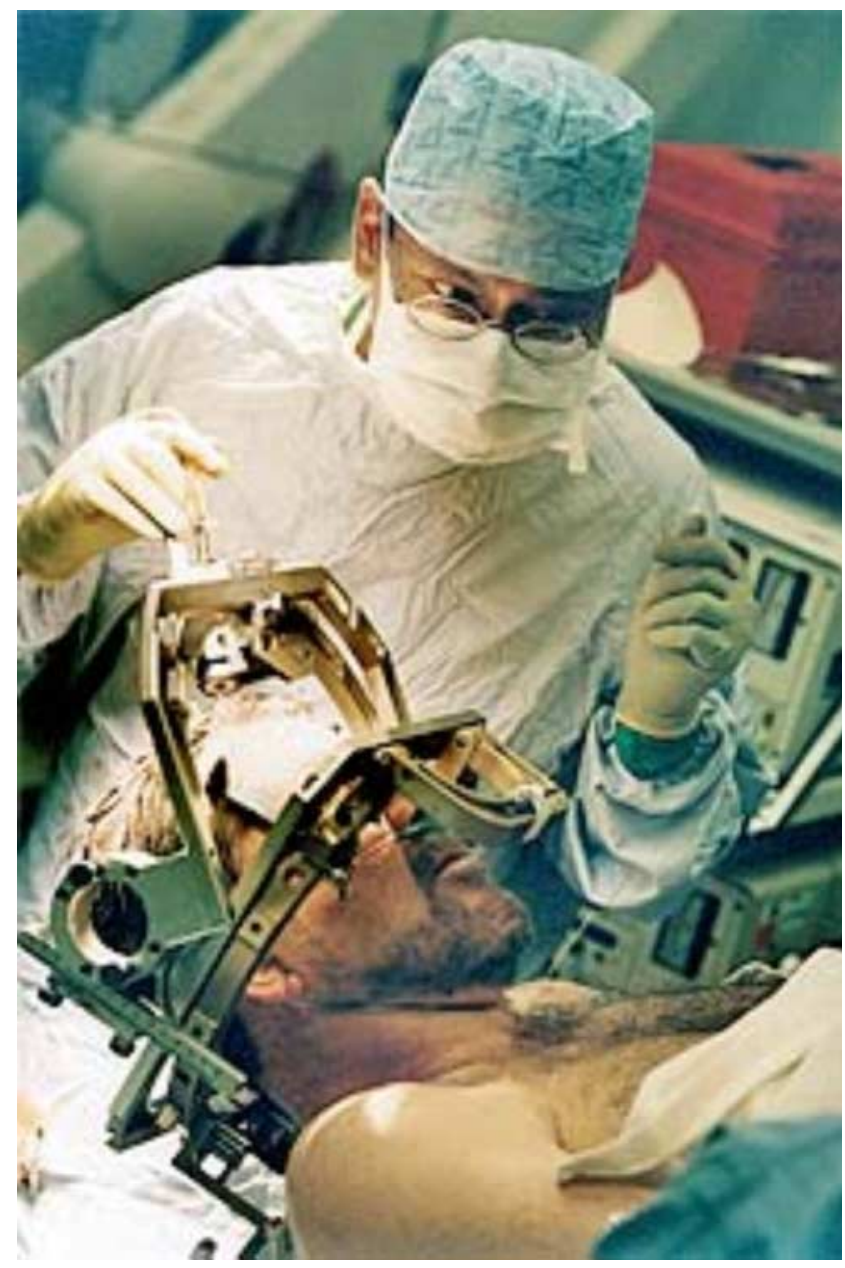

Figure 3 Electrode implantation for deep brain stimulation in Parkinson's disease [in colour online]

new roles in the disease for brain structures related to the basal ganglia, such as the pedunculopontine nucleus. ${ }^{59}$ These findings provide exciting possibilities for novel therapeutic targets for DBS that are already beginning to reach the clinic. ${ }^{60,61}$

\section{RESTORATIVE SURGERY-QUO VADIS?}

Potential cellular and molecular therapies for the disease include gene therapy, neural tissue transplantation and nanotechnology. Of these, both neural transplantation and gene therapy have reached clinical trials.

Neural transplantation aims to replace the nigrostriatal neurons that release the neurotransmitter dopamine and then degenerate in this disease. The many donor cell sources under consideration include porcine neural xenografts, human fetal tissue and human stem cells. For fetal tissue, anatomical and functional imaging studies have supported clinical evidence of graft survival and functionality. ${ }^{62}$ However, clinical trials have resulted in complica- dyskinesias are hypothesized to arise from altered dopamine release, but the mechanisms remain contentious and some have suggested that they may only occur in certain subgroups of patients. ${ }^{65}$ The trials performed have been upon small numbers of patients with little consistency in graft amounts and grafting techniques used. Furthermore, the technique may be limited by ethical concerns and limited donor sources.

One promising form of gene therapy that may soon reach clinical trials involves introducing enzymes required for dopamine synthesis into the striatum. Good results have been demonstrated in restoring motor function in a rodent model of parkinsonism. ${ }^{66}$ Other gene therapies currently being trialled in patients aim to:

- replace neurotransmitters like gamma-aminobutyric acid (GABA) to alter basal ganglia neuronal circuitry functions

- or to insert neural growth factors like glial cell-line derived neurotrophic factor (GDNF) to arrest or reverse the degeneration of nigrostriatal neurons.

Viral vectors are considered more likely to be efficient, practical and safe than constant infusions of recombinant factors for the delivery of gene therapy at present, and may also confer the advantage of requiring a single treatment only. Furthermore, it is suggested that neurotrophic gene therapy is, in principle, less likely to cause unwanted dyskinesias: it aims to restore pre-existing neural function, rather than replace it as neural transplantation aims to do. Further research is required to confirm both that gene therapy is safe and that its functional restoration is lasting.

Looking to the future beyond neural transplantation and gene therapy, molecular nanotechnology is the threedimensional control of atoms and molecules to produce materials with novel properties. Alongside advances in biological imaging that such technologies will enable, nanomaterials like nanotubes could be used therapeutically as ligand carriers or vectors for drug or gene delivery. 67,68 Nanomanufacturing aims to produce functional biological macromolecules that can operate in vivo while being controlled ex vivo; one possibility would be the manufacture of dopamine producing nigrostriatal neurons whose level of activity could be modulated exogenously as required. The technology remains experimental and far from clinical trials at present, but nanosurgery holds great promise for the future of surgery in Parkinson's disease.

Amidst all the excitement surrounding cellular and molecular treatments for Parkinson's disease, it should be noted that merely attempting to restore dopamine release from nigrostriatal neurons may remain limited in the extent to which it addresses the problems. Thus, shifts of research focus may be preferable: first, towards halting disease 
progression; and, secondly, towards understanding its aetiology with a view to disease prevention. ${ }^{69}$ As the best models of Parkinson's disease are currently primate models, they will continue to be vital, both to characterizing the onset and progression of parkinsonian degeneration, and in the development of preventative strategies.

\section{CONCLUSIONS}

Much has been learnt about Parkinson's disease from surgical interventions. The ablative procedures undertaken before the era of levodopa helped delineate anatomical structures implicated in the disease. Alongside serendipitous clinical discoveries, empirical observations in patients and technological advances, valuable progress has been made because of controlled experiments enabled by the availability of an accurate animal model. The example of DBS of the subthalamic nucleus demonstrates a therapy whereby primate research has not only been essential to advancing our theoretical framework, but also provided evidence to justify clinical trials in patients leading to successful treatment.

The surgical treatment of DBS provides amelioration of Parkinson's disease motor symptoms and relief from motor complications of medical treatment. Measurements made from indwelling electrodes in patients continue to give new insights into the functional anatomy and pathophysiology of the disease. Other targeted surgical therapies like gene therapy, neural transplantation and nanotechnology show much promise; but they require robust demonstration of their safety and efficacy in animal models before progressing to clinical trials. Novel surgical techniques have playedand continue to play - a crucial role in deepening our understanding of the parkinsonian brain. Their implementation requires carefully controlled clinical trials with appropriate patient selection, blinding and randomization. There are many unanswered issues relating to both motor and non-motor manifestations of Parkinson's disease and the renaissance in surgery gives much hope in that we may begin to address them.

Contributors EP and TA conceived and wrote the paper. TA is its guarantor.

Funding This review was written without involvement from any funding source.

\section{Competing interests None.}

\section{REFERENCES}

1 Samii A, Nutt JG, Ransom BR. Parkinson's disease. Lancet 2004;363:1783-93
2 Parkinson J. An essay on the shaking palsy. London: Sherwood Neely \& Jones, 1817

3 Cotzias GC, Van WM, Schiffer LM. Aromatic amino acids and modification of parkinsonism. N Engl J Med 1967;276:374-9

4 Thanvi BR, Lo TCN. Long term motor complications of levodopa: clinical features, mechanisms, and management strategies. Postgrad Med J 2004;80:452-8

5 Jackson JH. Observations on the physiology and pathology of hemichorea. Edinburgh Med J 1868;14:294-303

6 Hunt R. Progressive atrophy of the globus pallidus. A contribution to the functions of the corpus striatum. Brain 1917;40:58-148

7 Wilson SAK. An experimental research into the anatomy and physiology of the corpus striatum. Brain 1914;36:427-92

8 Horsley V, Clarke RH. The structure and functions of the cerebellum examined by a new method. Brain 1908;31:45-124

9 Wilson SAK. Disorders of motility and muscle tone with special reference to the striatum. Lancet 1925;ii:1-10

10 Bucy PC, Case TJ. Tremor: Physiologic mechanism and abolition by surgical means. Arch Neurol Psychiat 1939;41:721-46

11 Clower WT. Lesions as therapy: surgical intervention in Parkinson's disease prior to L-dopa. J Hist Neurosci 2002;11:375-91

12 Meyerson A, Berlin DD. Case of postencephalitic Parkinson's disease treated by total thyroidectomy. N Engl J Med 1934;210:1205-6

13 Laitinen LV. Surgical treatment, past and present, in Parkinson's disease. Acta Neurol Scand Suppl 1972;51:43-58

14 Cooper IS. Ligation of the anterior choroidal artery for involuntary movements: parkinsonism. Psychiatr Q 1953;27:317-19

15 Spiegel EA, Wycis HT, Marks M, Lee AJ. Stereotaxic apparatus for operations on human brain. Science 1947;106:349-50

16 Leksell L. A stereotaxic apparatus for intracerebral surgery. Acta Chir Scand 1949;99:229-33

17 Svennilson E, Torvik A, Lowe R, Leksell L. Treatment of parkinsonism by stereotatic thermolesions in the pallidal region. A clinical evaluation of 81 cases. Acta Psychiatr Scand 1960;35:358-77

18 Laitinen LV. Leksell's unpublished pallidotomies of 1958-1962. Stereotact Funct Neurosurg 2000;74:1-10

19 Hassler R, Riechert T. Indikationen und Lokalisations methode der gezielten Hirnoperationene. Nervenarzt 1954;25:441

20 de Bie RM, de Haan RJ, Schuurman PR, Esselink RA, Bosch DA, Speelman JD. Morbidity and mortality following pallidotomy in Parkinson's disease: a systematic review. Neurology 2002;58:1008-12

21 Matsumoto K, Shichijo F, Fukami T. Long-term follow-up review of cases of Parkinson's disease after unilateral or bilateral thalamotomy. $J$ Neurosurg 1984;60:1033-44

22 Marsden CD. Primate models of neurological disorders. Introduction. Adv Neurol 1975;10:3-4

23 Sherrington CS. Decerebrate rigidity and reflex co-ordination of movements. J Physiol 1898;22:319-32

24 Aring CD, Fulton JF. Relation of the cerebrum to the cerebellum: Cerebellar tremor in the monkey and its absence after removal of the principal excitable areas of the cerebral cortex (Areas 4 and $5 a$, upper part); Accentuation of cerebellar tremor following lesions of the premotor area (Area 6a, upper part). Arch Neurol Psychiat 1936; $35: 439-66$

25 Denny-Brown D. The Basal Ganglia and Their Relation To Disorders of Movement. Oxford: Oxford University Press, 1962

26 Carlsson A, Lindquist M, Magnusson T. 3,4-Dihydroxy-phenylalanine and 5-hydroxytryptophan as reverse antagonists. Nature 1957; 180:1200-1

27 Langston JW, Ballard P, Tetrud JW, Irwin I. Chronic parkinsonism in humans due to a product of meperidine-analog synthesis. Science 1983;219:979-80 
28 Burns RS, Chiueh CC, Markey SP, Ebert MH, Jacobowitz DM, Kopin IJ. A primate model of parkinsonism: selective destruction of dopaminergic neurons in the pars compacta of the substantia nigra by N-methyl-4-phenyl-1,2,3,6-tetrahydropyridine. Proc Natl Acad Sci U $S$ A 1983;80:4546-50

29 Mitchell IJ, Jackson A, Sambrook MA, Crossman AR. The role of the subthalamic nucleus in experimental chorea. Evidence from 2deoxyglucose metabolic mapping and horseradish peroxidase tracing studies. Brain 1989;112:1533-48

30 DeLong MR. Primate models of movement disorders of basal ganglia origin. Trends Neurosci 1990;13:281-5

31 Albin RL, Young AB, Penney JB. The functional anatomy of basal ganglia disorders. Trends Neurosci 1989;12:366-75

32 Alexander GE, Crutcher MD. Functional architecture of basal ganglia circuits: neural substrates of parallel processing. Trends Neurosci 1990; 13:266-71

33 Obeso JA, Rodriguez-Oroz MC, Rodriguez M, Arbizu J, GimenezAmaya JM. The basal ganglia and disorders of movement: pathophysiological mechanisms. News Physiol Sci 2002;17:51-5

34 Ring HA, Serra-Mestres J. Neuropsychiatry of the basal ganglia. J Neurol Neurosurg Psychiatry 2002;72:12-21

35 Bergman H, Wichmann T, DeLong MR. Reversal of experimental parkinsonism by lesions of the subthalamic nucleus. Science 1990;249:1436-8

36 Aziz TZ, Peggs D, Sambrook MA, Crossman AR. Lesion of the subthalamic nucleus for the alleviation of 1-methyl-4-phenyl-1,2,3,6tetrahydropyridine (MPTP)-induced parkinsonism in the primate. Mor Disord 1991;6:288-92

37 Laitinen LV, Bergenheim AT, Hariz MI. Leksell's posteroventral pallidotomy in the treatment of Parkinson's disease. J Neurosurg 1992;76:53-61

38 Bingaman KD, Bakay RA. The primate model of Parkinson's disease: its usefulness, limitations, and importance in directing future studies. Prog Brain Res 2000;127:267-97

39 Collier TJ, Steece-Collier K, Kordower JH. Primate models of Parkinson's disease. Exp Neurol 2003;183:258-62

40 Emborg ME. Evaluation of animal models of Parkinson's disease for neuroprotective strategies. J Neurosc Meth 2004;139:121-43

41 Linazasoro G. Recent failures of new potential symptomatic treatments for Parkinson's disease: causes and solutions. Mov Disord 2004;19:74354

42 Langston JW, Quik M, Petzinger G, Jakowec M, Di Monte DA. Investigating levodopa-induced dyskinesias in the parkinsonian primate. Ann Neurol 2000;47(Suppl 1):S79-89

43 Jenner $P$. The MPTP-treated primate as a model of motor complications in Parkinson's disease: primate model of motor complications. Neurology 2003;61(Suppl 3):S4-11

44 Cooper IS. Effect of chronic stimulation of anterior cerebellum on neurological disease. Lancet 1973;i:206

45 Benabid AL, Pollak P, Louveau A, Henry S, de Rougement J. Combined (thalamotomy and stimulation) stereotactic surgery of the VIM thalamic nucleus for bilateral Parkinson disease. Appl Neurophysiol 1987;50:344-6

46 Walter BL, Vitek JL. Surgical treatment for Parkinson's disease. Lancet Neurol 2004;3:719-28

47 Rodriguez-Oroz MC, Obeso JA, Lang AE, et al. Bilateral deep brain stimulation in Parkinson's disease: a multicentre study with 4 years follow-up. Brain 2005;128:2240-9

48 Lang AE, Widner H. Deep brain stimulation for Parkinson's disease: patient selection and evaluation. Mov Disord 2002;17(Suppl 3):S94-101
49 Stowe RL, Wheatley K, Clarke CE, et al. Surgery for Parkinson's disease: lack of reliable clinical trial evidence. J Neurol Neurosurg Psychiatry 2003;74:519-21

50 [http://www.pdsurg.bham.ac.uk]

51 Okun MS, Foote KD. Subthalamic Nucleus vs Globus Pallidus Interna Deep Brain Stimulation, the Rematch. Arch Neurol 2005;62:533-6

52 Jahanshahi M, Ardouin CMA, Brown RG, et al. The impact of deep brain stimulation on executive function in Parkinson's disease. Brain 2005; 123:1142-54

53 Diamond A, Jankovic J. The effect of deep brain stimulation on quality of life in movement disorders. J Neurol Neurosurg Psychiat 2005;76:1188-93

54 Rodriguez MC, Obeso JA, Olanow CW. Subthalamic nucleusmediated excitotoxicity in Parkinson's disease: a target for neuroprotection. Ann Neurol 1998;44:S175-88

55 Hilker R, Portman AT, Voges J, et al. Disease progression continues in patients with advanced Parkinson's disease and effective subthalamic nucleus stimulation. J Neurol Neurosurg Psychiat 2005;76:1217-21

56 Marsden CD, Obeso JA. The functions of the basal ganglia and the paradox of stereotaxic surgery in Parkinson's disease. Brain 1994;117:877-97

57 Brown P, Marsden CD. What do the basal ganglia do? Lancet 1998;351:1801-4

58 Brown P. Oscillatory nature of human basal ganglia activity: Relationship to the pathophysiology of Parkinson's disease. Movement Disorders 2003; 18:357-63

59 Jenkinson N, Nandi D, Miall RC, Stein JF, Aziz TZ. Pedunculopontine nucleus stimulation improves akinesia in a Parkinsonian monkey. Neuroreport 2004;15:2621-4

60 Jenkinson N, Nandi D, Aziz TZ, Stein JF. Pedunculopontine nucleus: a new target for deep brain stimulation for akinesia. Neuroreport 2005; 16:1875-6

61 Plaha P, Gill SS. Bilateral deep brain stimulation of the pedunculopontine nucleus for Parkinson's disease. Neuroreport 2005; 16:1883-7

62 Bjorklund A, Dunnett SB, Brundin P, et al. Neural transplantation for the treatment of Parkinson's disease. Lancet Neurol 2003;2:437-45

63 Olanow CW, Goetz CG, Kordower JH, et al. A double-blind controlled trial of bilateral fetal nigral transplantation in Parkinson's disease. Ann Neurol 2003;54:403-14

64 Freed CR, Greene PE, Breeze RE, et al. Transplantation of embryonic dopamine neurons for severe Parkinson's disease. N Engl J Med 2001; 344:710-19

65 Hagell P, Piccini P, Bjorklund A, et al. Dyskinesias following neural transplantation in Parkinson's disease. Nat Neurosci 2002;5:627-8

66 Azzouz M, Martin-Rendon E, Barber RD, et al. Multicistronic lentiviral vector-mediated striatal gene transfer of aromatic L-amino acid decarboxylase, tyrosine hydroxylase, and GTP cyclohydrolase I induces sustained transgene expression, dopamine production, and functional improvement in a rat model of Parkinson's disease. $J$ Neurosci 2002;22:10302-12

67 Silva GA. Introduction to nanotechnology and its applications to medicine. Surg Neurol 2004;61:216-20

68 Leary SP, Liu CY, Yu C, Apuzzo ML. Toward the emergence of nanoneurosurgery: part I- progress in nanoscience, nanotechnology, and the comprehension of events in the mesoscale realm. Neurosurgery 2005; $57: 606-34$

69 Lang AE, Obeso JA. Challenges in Parkinson's disease: restoration of the nigrostriatal dopamine system is not enough. Lancet Neurol 2004;3:309-16 